\title{
Bruk av litium i Oslo og i Sogn og Fjordane
}

\begin{abstract}
Sammendrag
Bakgrunn. Bruk av litium har tidligere vært registrert ved hjelp av salgsstatistikk. Reseptregisteret gir mulighetene til å undersøke forbruk på personnivå. I denne artikkelen ble data fra reseptregisteret sammenstilt med to befolkningsbaserte undersøkelser med hensyn til psykiatrisk sykelighet $\mathrm{i}$ henholdsvis Oslo og Sogn og Fjordane.
\end{abstract}

Materiale og metode. Alle personer i alderen 18-65 år i Oslo eller Sogn og Fjordane som mottok minst én resept på litium mellom juli 2005 og juni 2006, ble identifisert. Fylkes- og kjønnsspesifikk prevalens og insidens av bruk av litium og gjennomsnittlig dose ble regnet ut. En del farmakoepidemiologiske mål ble avledet.

Resultater. I Oslo var det 1,5 brukere av litium per 1000 innbyggere, mens det samme tallet i Sogn og Fjordane var 5,5. Insidensen var høyest for menn i Sogn og Fjordane. Mengde litium utlevert til hver pasient var høyere i Oslo enn i Sogn og Fjordane og høyere for menn enn for kvinner.

Fortolkning. Selv om forekomsten av bipolar lidelse er noe høyere i Sogn og Fjordane enn i Oslo, synes det å være mye større mulighet for å bli behandlet med litium i Sogn og Fjordane enn i Oslo for slik sykdom. Tidligere estimater av forekomsten av bipolar lidelse i Sogn og Fjordane er antakelig for lave. I tillegg kan det hende bruken har en bredere indikasjon i dette fylket.

\author{
Jørgen G. Bramness* \\ jorgen.bramness@fhi.no \\ Avdeling for legemiddelepidemiologi \\ Nasjonalt folkehelseinstitutt \\ Postboks 4404 Nydalen \\ 0881 Oslo \\ * Nåværende adresse: \\ Senter for rus og avhengighetsforskning \\ Universitetet i Oslo \\ Kirkeveien 166 \\ 0407 Oslo
}

At det finnes fylkesforskjeller i bruk av medisiner av ulike slag, inkludert psykotrope legemidler, er en erkjennelse som er like årviss som utgivelsen av publikasjonen Legemidler $i$ Norge fra Avdeling for legemiddelepidemiologi ved Nasjonalt folkehelseinstitutt (1). Likeledes kjenner vi til at det er rapportert forskjeller i psykiatrisk sykelighet mellom for eksempel Oslo (2) og Sogn og Fjordane (3) (tab 1). Disse to datakildene er imidlertid ikke tidligere sammenstilt.

Litium er et medikament med relativt smal indikasjon. Det brukes i hovedsak til behandlingen av mani (4) og til forebyggende behandling ved bipolar lidelse (5) og på noen andre indikasjoner. Dette er nedfelt $i$ behandlingsretningslinjer (6). Muligens kunne mål på bruk av litium representere mål på forekomsten av bipolar lidelse? Vi har tidligere brukt denne typen legemiddelmål som et mål på sykelighet f.eks. ved å studere insulinbruk hos unge som et uttrykk for forekomsten av diabetes mellitus type 1 (7).

Tidligere har utviklingen i bruk av medikamenter i Norge vært studert ved hjelp av nasjonale salgsdata (Grossiststatistikken ved Nasjonalt folkehelseinstitutt). Etter opprettelsen av Reseptregisteret kan man få tilgang til mer detaljert informasjon om legemiddelbruken i fylkene, ved å inkludere kjønn, alder og doser hos nye (insidente) eller alle (prevalente) brukere. En del farmakoepidemiologiske mål kan utledes fra denne informasjonen.

Denne undersøkelsen viser farmakoepidemiologiske data for bruken av litium i Oslo og i Sogn og Fjordane. Resultatene diskuteres med angivelser av forekomst av bipolar lidelse i de samme fylkene.

\section{Materiale og metode}

Data ble hentet fra det nasjonale reseptbaserte legemiddelregisteret (Reseptregisteret) ved Nasjonalt folkehelseinstitutt. Alle resepter på litiumpreparater (Litarex (litium- sitrat), Lithionit (litiumsulfat), litiumkarbonat og Priadel (litiumkarbonat)) utlevert fra norske apotek i perioden 1.7. 2005-30.6. 2006 til pasienter med folkeregisteradresse i Oslo eller Sogn og Fjordane og som var i alderen 18-65 år 1.1. 2006 ble identifisert. Følgende data ble innhentet: kjønn, alder, dato for utlevering, medikamentinformasjon (salgsnavn, pakningsstørrelse, antall pakninger, ATC-kode, antall definerte døgndoser (DDD) utlevert). Litium som ble utlevert til inneliggende pasienter (sykehjem eller sykehus), ble ikke registrert på personnivå, og personer som har fått utlevert medikamentene bare i institusjon, vil ikke være representert. Utleveringer til institusjoner utgjorde $6,1 \%$ av alle utleveringer i perioden.

Antall personer som fikk utlevert minst en resept på litium i studieperioden, ble holdt opp mot folketall, og kjønns- og aldersspesifikk prevalens ble regnet ut. Insidensrater ble estimert på grunnlag av personer som fikk sin første resept utlevert i de siste fire månedene av studieperioden. Den underliggende forutsetning er at prevalente brukere forventes å hente minst en resept i løpet av de første åtte månedene av studieperioden (8). Et estimat for behandlingsvarighet ble beregnet etter formelen $d=p /(1-p) * I$, hvor $d$ er varighetsesimatet, $\mathrm{p}$ er punktprevalens (terapeutisk intensitet) og I er insidensrate (8). Skjevheter i bruken ble beregnet ved konstruksjon av såkalte Lorenzkurver (8). Denne viser andelen medikamentbrukere ordnet etter mengde brukt. Et høyt Lorenzkurve $1 \%$-estimat viser at noen få brukere står for mye av bruken, mens et høyt estimat for Lorenz $50 \%$ antyder at det er mye sporadisk bruk av medikamentet.

\section{Resultater}

Rundt 1,5 personer per 1000 innbyggere $\mathrm{i}$ Oslo i alderen 18-65 år fikk i studieperioden utlevert minst én resept på litium. For Sogn og Fjordane var det samme tallet 5,5

\section{Hovedbudskap}

- Behandling med litium er langt vanligere i Sogn og Fjordane enn i Oslo

- Behandlingshyppigheten i Sogn og Fjordane viser at tidligere estimater for forekomsten av bipolar lidelse i fylket kan være for lave 


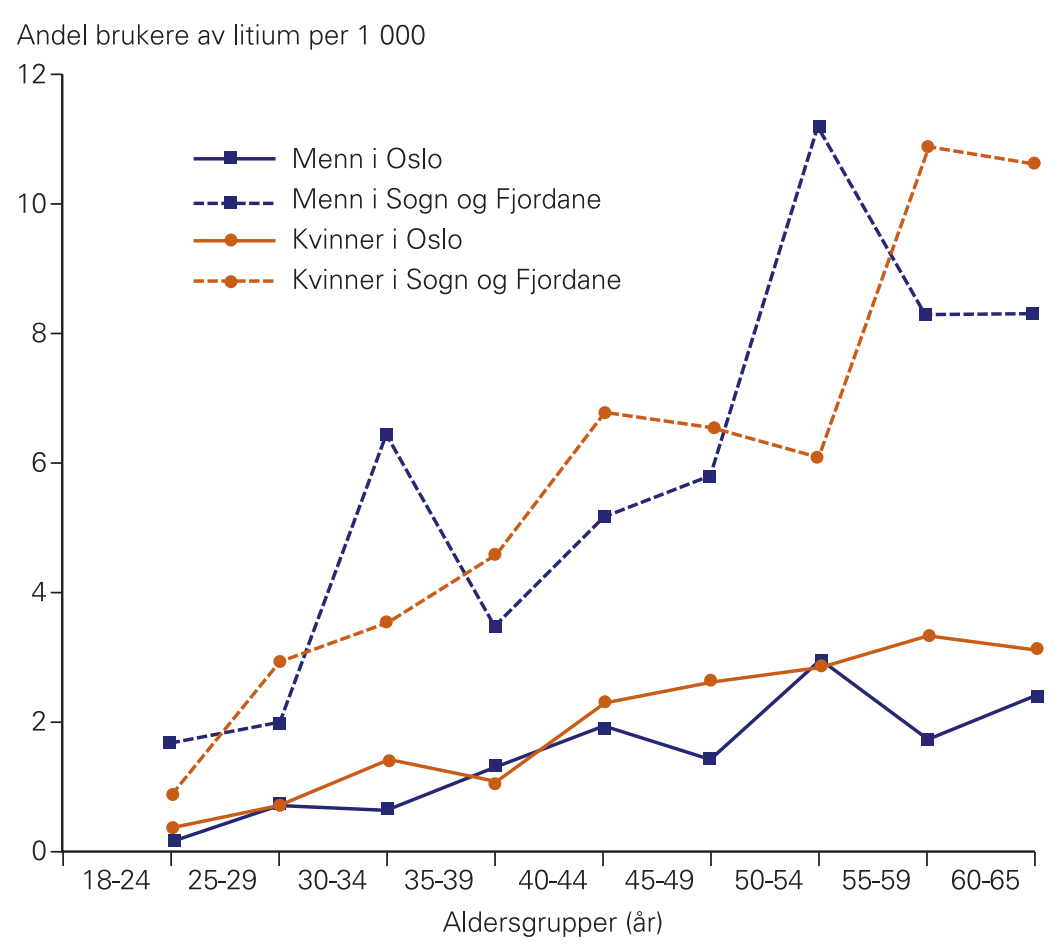

Figur 1 Andel av befolkningen i Oslo og Sogn og Fjordane som har mottatt minst én resept på litium i undersøkelsesperioden etter kjønn og aldersgrupper

(tab 2). I den aktuelle alderskohorten var det ingen spesielle aldersforskjeller mellom kjønnene. Insidensraten var høyere i Sogn og Fjordane enn i Oslo. Mens insidensen var lik for begge kjønn i Oslo, var den omtrent

dobbelt så høy for menn som for kvinner i Sogn og Fjordane, henholdsvis seks og tre ganger høyere enn tilsvarende Oslo-tall. Dette får konsekvenser også for de avledede verdiene, så som estimatene for varighet av

Tabell 1 Livstidsprevalenser og 12-månedersprevalenser av bipolar lidelse for menn og kvinner $i$ henholdsvis Oslo og Sogn og Fjordane. Tallene er hentet fra Kringlen og medarbeideres epidemiologiundersøkelser $(2,3)$

\begin{tabular}{lcccccc} 
& \multicolumn{3}{c}{ Livstidsprevalens (\%) } & \multicolumn{3}{c}{ 12-månedersprevalens (\%) } \\
& Alle & Menn & Kvinner & Alle & Menn & Kvinner \\
Oslo & 1,6 & 1,7 & 1,5 & 0,9 & 0,8 & 1,0 \\
Sogn og Fjordane & 0,2 & 0,0 & 0,4 & 0,1 & 0,0 & 0,2
\end{tabular}

behandlingen som ble estimert langt kortere for menn i Sogn og Fjordane enn for kvinner der og for begge kjønn i Oslo. Doseringen av litium fremstår som høyere i Oslo og blant menn. Estimatene for Lorenz $1 \%$ antyder ikke store skjevheter i mengde utlevert til hver pasient, og Lorenz $50 \%$ antyder lite sporadisk bruk.

Figur 1 viser kjønns- og aldersspesifikk andel av befolkningen i de to fylkene som har fått utlevert minst én resept på medikamentet. I Oslo fikk flere kvinner enn menn utlevert medikamentet, mens det var omvendt i Sogn og Fjordane.

\section{Diskusjon}

Det selges over tre ganger så mye litium per innbygger i Sogn og Fjordane sammenliknet med Oslo. Dette reflekteres i antall brukere som er mellom tre og fire ganger så høyt $\mathrm{i}$ Sogn og Fjordane sammenliknet med Oslo. Selv om forekomsten av bipolar lidelse antakelig er høyere enn det som er rapportert av Kringlen og medarbeidere (3), er det langt større mulighet for å bli behandlet for sin bipolare lidelse med litium i Sogn og Fjordane enn i Oslo. Muligheten øker relativt proporsjonalt med alder. Det er spesielt at flere menn enn kvinner behandles med litium i Sogn og Fjordane.

I Kringlen og medarbeideres undersøkelse fra Sogn og Fjordane ble det funnet kun én kvinne og ingen menn med bipolar lidelse $\mathrm{i}$ et utvalg av 1080 personer i alderen 18-65 år (3). Omregnet til hele fylket skulle dette gi et estimat på omtrent 60 med diagnosen i Sogn og Fjordane. Ved å regne ut et $95 \%$ konfidensintervall for dette estimatet finner vi at den sanne forekomsten av bipolar lidelse i den aktuelle alderskohorten sannsynligvis ligger på $0-180$ personer. I vår undersøkelse finner vi 350 personer som har fått minst én resept på litium. Til tross for at litium også har andre indikasjoner, som behandling av depresjon $(9-11)$ og muligens aggresjon (12), og at det kan være forskjeller i forståelsen av bipolarbegrepet mellom de to fylkene, er det grunn til å anta

Tabell 2 Antall individer (18-65 år) som har mottatt minst én resept på litium, gjennomsnittsalder, andel av befolkningen, salg av litium per 1000 innbyggere per døgn (i DDD), insidens, varighetsestimat, gjennomsnittlig dose og estimater Lorenz $1 \%$ og 50 \% i 2006 for Oslo og for Sogn og Fjordane

\begin{tabular}{|c|c|c|c|c|c|c|c|c|c|}
\hline & $\begin{array}{c}\text { Antall brukere } \\
(\% \text { av alle } \\
\text { brukere })\end{array}$ & $\begin{array}{l}\text { Alder } \\
\text { (år) }\end{array}$ & $\begin{array}{l}\text { Andel av befolk- } \\
\text { ningen (per } 1000 \\
\text { innbyggere) }\end{array}$ & $\begin{array}{c}\text { Terapeutisk } \\
\text { intensitet } \\
\text { (DDD/1 } 000 \\
\text { inbyggere/ } \\
\text { døgn)1 }\end{array}$ & $\begin{array}{l}\text { Insidens } \\
\text { (per } 1000 \\
\text { personår) }\end{array}$ & 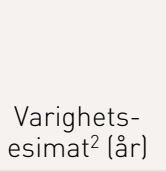 & $\begin{array}{c}\text { Dose } \\
\text { Snitt (SD) } \\
\text { (DDD/år) }\end{array}$ & $\begin{array}{l}\text { Lorenz } 1 \% \\
\text { (\% av bru- } \\
\text { kerne) }\end{array}$ & $\begin{array}{l}\text { Lorenz } 50 \% \\
\text { (\% av bru- } \\
\text { kerne) }\end{array}$ \\
\hline \multicolumn{10}{|l|}{ Oslo } \\
\hline Menn & $245(44,1)$ & 46,3 & 1,3 & 1,31 & 0,31 & 4,22 & 358 (210) & 3,44 & 74,41 \\
\hline Kvinner & $311(55,9)$ & 46,9 & 1,7 & 1,46 & 0,28 & 5,22 & 313 (177) & 3,05 & 73,83 \\
\hline \multicolumn{10}{|c|}{ Sogn og Fjordane } \\
\hline Menn & $181(51,7)$ & 47,0 & 5,5 & 5,17 & 1,82 & 2,84 & 344 (179) & 2,50 & 72,10 \\
\hline Kvinner & $169(48,3)$ & 48,6 & 5,5 & 4,51 & 0,89 & 5,09 & 297 (145) & 2,96 & 71,39 \\
\hline
\end{tabular}

Det samme som punktprevalens

2 Beregnes ut fra formelen $d=p /(1-p) *$, hvor $d$ er varighetsestimatet, $p$ er punktprevalens (her $=$ terapeutisk intensitet) og I er insidensrate 
at Kringlen og medarbeideres estimat for bipolar lidelse i Sogn og Fjordane er for lavt. Selv store befolkningsbaserte undersøkelser av representative utvalg vil ha problemer med seleksjonsskjevheter. Det er vanskeligere å si om de tilsvarende tallene for Oslo (2) også gir samme underestimering. Det er et tidsspenn mellom Kringlens undersøkelse (midten av 1990-årene) og vår undersøkelse (2005-06), men bruken av litium har gått marginalt ned i denne perioden slik at endringer i forekomst ikke kan forklare uoverensstemmelsen. I sum kan vi si at funnene i den foreliggende undersøkelsen kan gi grunnlag for en nyttig diskusjon rundt prevalensestimatene for bipolar lidelse og muligens kan bidra til en korreksjon av klinisk praksis i begge fylker.

Det er lite informasjon om pasientene inkludert i Reseptregisteret. Fordelen med registeret er at det gir en kontinuerlig oppdatert informasjon for hele populasjonen. Selv om man skal være uhyre forsiktig med å bruke tall fra registeret til å si noe om utbredelsen av sykdommer, har denne undersøkelsen vist at tallene i hvert fall kan brukes til en kvalitetskontroll av funn i befolkningsbaserte undersøkelser.

Forskjellen i bruken av litium mellom Oslo og Sogn og Fjordane har vært stabil i mange år etter at leger i Sogn og Fjordane endret sin forskrivningspraksis fra omtrent 1980 og mer enn tredoblet forordningen av dette preparatet i løpet av en tiårsperiode. Noen har hevdet at fylkets leger endret $\sin$ diagnostiske praksis. Der man tidligere hadde sett for eksempel unipolare depresjoner, ustabil personlighetsforstyrrelse og rusmisbruk, så man nå bipolar lidelse. Også andre forskjeller i behandlingstradisjoner, ulikt tilbud om tjenester, ulik oppmerksomhet på sykdom, ulike grenser for igangsetting av medikamentelle tiltak og bruk av ulike medikamenter, dels på grunn av ulike muligheter til å følge opp pasientene og igjen dels på bakgrunn av ulike behandlingstradisjoner, kan være med på å forklare forskjellene.

Til slutt er det grunn til å minne om at litium fremdeles er det best dokumenterte midlet til profylaktisk behandling av bipolar lidelse (13), og at det av mange fortsatt er ansett som i hvert fall en viktig del av den farmakologiske behandlingen av bipolare pasienter $(14,15)$. Det er med andre ord vanskelig å tenke seg at bare en rasjonell farmakoterapeutisk begrunnelse ligger bak ulikhetene.

Oppgitte interessekonflikter: Ingen

\section{Litteratur}

1. Rønning M, Sakshaug S, Strøm H et al. Legemiddelforbruk i Norge 2003-2007. Oslo: Folkehelseinstituttet, 2008

2. Kringlen E, Torgersen S, Cramer V. A Norwegian psychiatric epidemiological study. Am J Psychiatry 2001; 158: $1091-8$

3. Kringlen E, Torgersen S, Cramer V. Mental illness in a rural area: a Norwegian psychiatric epidemiological study. Soc Psychiatry Psychiatr Epidemiol 2006; 41: 713-9.
4. McElroy SL, Keck PE jr. Pharmacologic agents for the treatment of acute bipolar mania. Biol Psychiatry 2000; 48: 539-57

5. Carney S, Goodwin G. Lithium - a continuing story in the treatment of bipolar disorder. Acta Psychiatr Scand 2005; 111: 7-12.

6. Hirschfeld R, Bowden C, Gitlin M et al. Practice guideline for the treatment of bipolar disorder. Am J Psychiatry 2002; 159: 64-110.

7. Strom $H$, Engeland A, Eriksen E et al. Hvor mange og hvem behandles medikamentelt for diabetes mellitus? Tidsskr Nor Lægeforen 2006; 126 : 768-70.

8. Hallas J, Støvring H. Templates for analysis of individual-level prescription data. Basic Clin Pharmacol Toxicol 2006; 98: 260-5

9. Goodwin FK, Murphy DL, Bunney WE jr. Lithiumcarbonate treatment in depression and mania. A longitudinal double-blind study. Arch Gen Psychiatry 1969; $21: 486-96$.

10. Mendels J. Lithium in the treatment of depression. Am J Psychiatry 1976; 133: 373-8.

11. Bauer M, Dopfmer S. Lithium augmentation in treatment-resistant depression: meta-analysis of placebo-controlled studies. J Clin Psychopharmacol 1999; 19: 427-34

12. Bond AJ, Lader MH, da Silveira JCC. Aggression. Individual differences, alcohol and benzodiazepines. London: Psychology Press; 1997

13. Bengtson F, Hagberg B, Henriksson F et al. Behandling av depressionssjukdomar. Stockholm SBU, Statens beredning för medicinsk utvärdering. 2004

14. Lingjærde O. Psykofarmaka. Medikamentell behandling av psykiske lidelser. Oslo: Høyskoleforlaget, 2006.

15. Goodwin FK, Jamison K. Manic-depressive illness. Bipolar depression and recurrent depression. Oxford: Oxford University Press, 2007.

Manuskriptet ble mottatt 19.9. 2008 og godkjent 12.2. 2009. Medisinsk redaktør Odd Terje Brustugun. 